\section{Esophageal post-inflammatory polyposis in extensive and severe Crohn's disease treated with anti-tumor necrosis factor alpha}

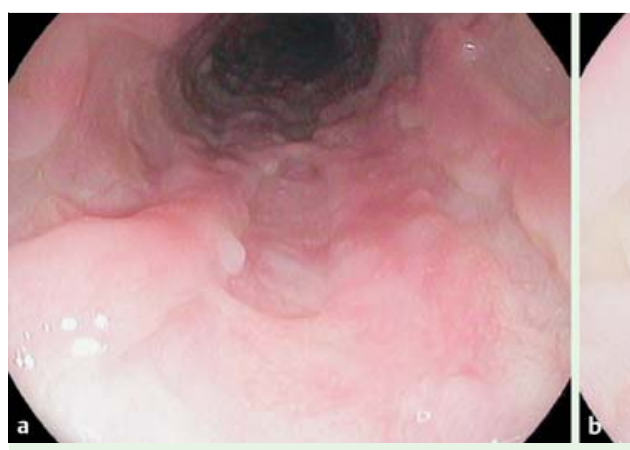

Fig. 1 Endoscopic views of the esophagus showing multiple linear areas of mucosal denudation, especially in the mid and distal esophagus.

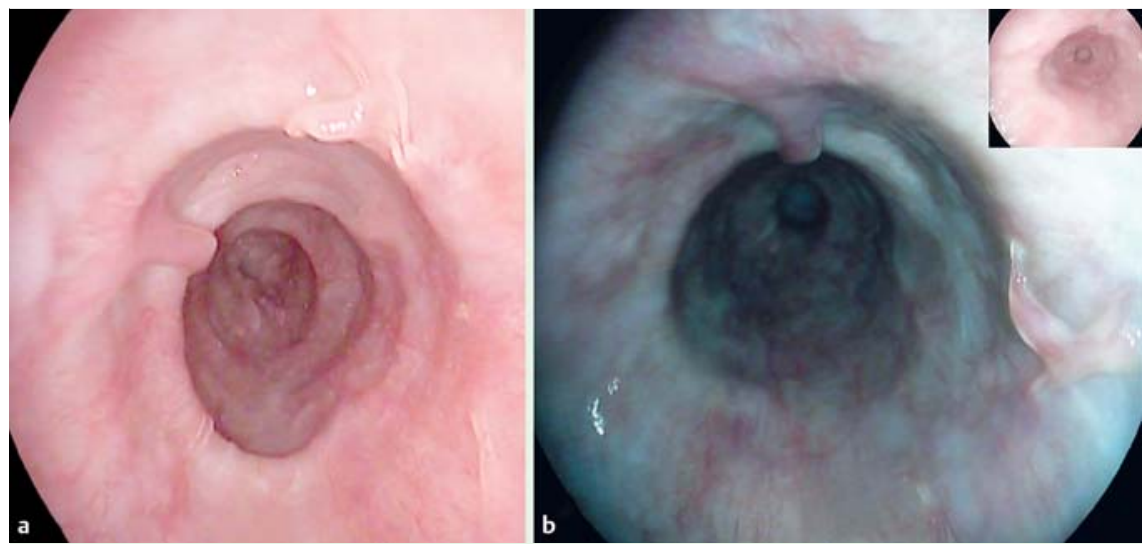

Fig. 2 Images from a repeat endoscopy after 1 year of anti-tumor necrosis factor alpha (TNF $\alpha$ ) treatment for extensive and severe Crohn's disease showing post-inflammatory polyps in the mid and distal esophagus.

Post-inflammatory polyposis (PIP) of the large bowel is a common endoscopic finding in patients with inflammatory bowel disease as it results from reparative processes following severe inflammation. To date, extra-intestinal localization of PIP is exceptional and poorly understood [1 -3]. Here we report the case of a 69-year-old man with a history of ileocolonic Crohn's disease who presented to our department with diarrhea, weight loss, severe pyrosis, and dysphagia. Ileocolonoscopy and cross-sectional imaging showed severe and extensive inflammatory lesions consistent with the diagnosis of Crohn's disease, while upper gastrointestinal endoscopy revealed multiple areas of mucosal denudation spread throughout the esophagus with no stigmata of gastroesophageal reflux disease or an infectious disorder $($ Fig. 1). Histopathological anal- ysis of biopsies that were taken from an area at least $2 \mathrm{~cm}$ above the squamocolumnar junction revealed a severe, acute and chronic cellular infiltrate with no evidence of a granuloma but suggesting for upper gastrointestinal tract involvement of Crohn's disease

The patient was initially treated with a course of systemic steroids plus full dosage of a proton pump inhibitor (PPI). Given the persistence of severe disease despite steroid treatment, he was started on anti-tumor necrosis factor alpha (TNF $\alpha$ ) therapy, to which he showed an immediate global clinical response. A repeat upper gastrointestinal endoscopy 1 year later revealed healing of the esophageal mucosa but the presence of widespread filiform polyps of $3-6 \mathrm{~mm}$ in size and subtle scars ( $\mathrm{Fig} .2$; - Video 1). Histopathological analysis of the resected polyps showed no sign of

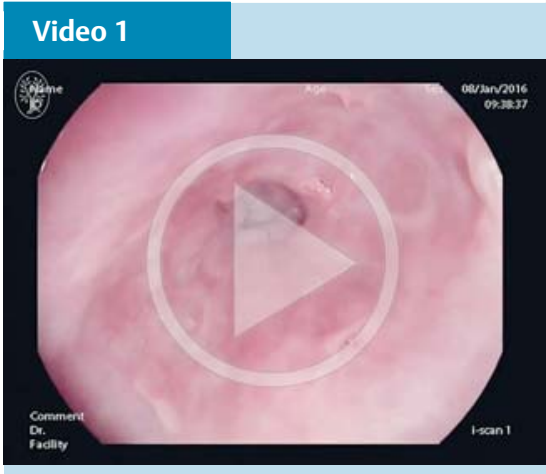

Repeat endoscopy after 1 year of anti-tumor necrosis factor alpha (TNF $\alpha$ ) treatment showing post-inflammatory polyps in the mid and distal esophagus.

active inflammation and microscopic architectural changes consistent with the diagnosis of esophageal PIP.

This case is interesting for several reasons. First, we have provided detailed image and video documentation of an exceptional case of esophageal PIP using high definition and digital chromoendoscopy with i-scan. Secondly, we documented the first case of esophageal Crohn's disease that healed with the use of antiTNF $\alpha$ therapy and resulted in PIPs. Third, this case focused on uncommon clinical manifestation of upper gastrointestinal Crohn's disease [4], which presented with symptoms of reflux disease non-responsive to PPIs, thus raising the clinical degree of suspicion.

Endoscopy_UCTN_Code_CCL_1AD_2AD

Competing interests: None

Paola Soriani $^{1}$, Gian Eugenio Tontini ${ }^{1}$, Helmut Neumann², Sauid Ishaq ${ }^{3,4}$, Maria Laura Annunziata ${ }^{1}$, Luca Pastorelli', ${ }^{1,5}$, Maurizio Vecchi, ${ }^{1,5}$

${ }^{1}$ Gastroenterology and Digestive Endoscopy Unit, IRCCS Policlinico San Donato, Milan, Italy

2 Department of Medicine, University Hospital Erlangen, Erlangen, Germany ${ }^{3}$ St. George's University, Grenada, West Indies 
${ }^{4}$ Birmingham City University, Birmingham, UK

${ }^{5}$ Department of Biomedical Sciences for Health, University of Milan, Milan, Italy

\section{References}

1 Cockey BM, Jones BM, Bayless TM et al. Filiform polyps of the esophagus with inflammatory bowel disease. AJR Am J Roentgenol 1985; 144: 1207-1208

2 Decker GA, Loftus EV Jr, Pasha TM et al. Crohn's disease of the esophagus: clinical features and outcomes. Inflamm Bowel Dis 2001; 7: 113-119

3 Jaber R, Gardiner G, Condon DS et al. Esophageal pseudopolyposis: a unique endoscopic finding in a patient with active Crohn's disease. Am J Gastroenterol 2006; 101: 2665 2666

4 Annunziata ML, Caviglia R, Papparella $L G$ et al. Upper gastrointestinal involvement of Crohn's disease: a prospective study on the role of upper endoscopy in the diagnostic work-up. Dig Dis Sci 2012; 57: 1618-1623

\section{Bibliography}

DOI http://dx.doi.org/

10.1055/s-0042-110487

Endoscopy 2016; 48: E261-E262

(c) Georg Thieme Verlag KG

Stuttgart · New York

ISSN 0013-726X

\section{Corresponding author}

\section{Paola Soriani, MD}

Gastroenterology and Digestive Endoscopy Unit IRCCS Policlinico San Donato

Via Morandi 30

San Donato Milanese

Milano 20097

Italy

paola.soriani@gmail.com 